\title{
Editorial
}

\section{Terahertz Technologies and Its Applications}

\author{
Victor Pacheco-Peña (1)
}

check for

updates

Citation: Pacheco-Peña, V. Terahertz Technologies and Its Applications. Electronics 2021, 10, 268. https:/ / doi.org/10.3390/electronics10030268

Academic Editor: Hirokazu Kobayashi Received: 23 December 2020

Accepted: 21 January 2021

Published: 23 January 2021

Publisher's Note: MDPI stays neutral with regard to jurisdictional claims in published maps and institutional affiliations.
School of Mathematics, Statistics and Physics, Newcastle University, Newcastle Upon Tyne NE1 7RU, UK; victor.pacheco-pena@newcastle.ac.uk

\section{Introduction}

The terahertz frequency range (0.1-10) THz has demonstrated the provision of many opportunities in various fields, such as high-speed communications, biomedicine, sensing, and imaging [1-6]. Historically, this frequency range, lying between the fields of electronics and photonics, was known as the "terahertz gap" because of the lack of sources, detectors and fabrication technologies.

However, considerable effort is now being devoted worldwide to improving this technology. Within this context, great progress has been made to fill the gap in this interesting spectral range, such as multiplexers and tuneable devices [7], among others. The aim of this Special Issue is to provide a platform to highlight the work being conducted within this range of the electromagnetic spectrum.

\section{In This Special Issue}

This Special Issue consists of thirteen papers covering a range of applications using $\mathrm{THz}$ technologies, including $\mathrm{THz}$ sensing and imaging, spectroscopy applications, and nondestructive testing. The contents of these papers are introduced below.

Reference [8] presents the modelling and evaluation of zero-biased Schottky diodes. Two different mounting techniques are considered: wire bonding and flip-chip. The experimental results are supported by numerical simulations demonstrating the validity of the proposed models. The improvement of radar cross-section using $\mathrm{THz}$ signals is shown and demonstrated in Reference [9], where the concept of adaptive gates is adopted to reduce the signal-to-noise ratio, thereby improving the accuracy of the measurement. The design of a frequency multiplier source working at $0.335 \mathrm{THz}$ is reported in Reference [10] with two different schemes; experimental validations of the proposed designs are provided.

This Special Issue also includes applications in THz spectroscopy. In Reference [11], the authors propose a mechanism to improve the accuracy of optical delay lines for $\mathrm{THz}$ spectroscopy applications by using an optical encoder. In Reference [12], the authors demonstrate a radiation power improvement of almost four times for spiral photoconductive antennas. Analyses of the structures are carried out using $\mathrm{THz}$ time-domain spectroscopy. In Reference [13], it is shown how THz spectroscopy can be used for nondestructive testing of the hollowing deterioration of stone relics (Yungang Grottoes in this case). Further applications for non-destructive testing using $\mathrm{THz}$ radiation are presented in Reference [14], where an optimal scanning technique for honeycomb sandwich composite panels is proposed. THz spectroscopy is applied in Reference [15] to evaluate the vulcanization and macrodispersion of silica for rubber products using $\mathrm{THz}$ absorption measurements.

The design, study, and experimental demonstration of a biased sub-harmonic mixer working at a frequency of $0.67 \mathrm{THz}$ is presented in Reference [16], demonstrating a conversion loss of $18.2 \mathrm{~dB}$ in the band between $0.650 \mathrm{THz}$ and $0.690 \mathrm{THz}$. A synthetic aperture THz imaging technique based on the light field imaging system is proposed in Reference [17]. An on-chip THz detector is presented in Reference [18]; it is designed by using both an onchip inset-feed rectangular patch antenna and a catadioptric lens. Reference [19] presents a nano displacement sensor using hetero-structure waveguides working in the $\mathrm{THz}$ frequency range of $0.8-1.1 \mathrm{THz}$, demonstrating a maximum sensitivity of around $1.2 \mathrm{GHz} / \mu \mathrm{m}$. 
A coupled stack oscillator working at $0.350 \mathrm{THz}$ is presented in Reference [20], showing an output power of $-0.8 \mathrm{dBm}$ at $0.3532 \mathrm{THz}$.

Funding: V.P-P. is supported by Newcastle University (Newcastle University Research Fellowship).

Acknowledgments: I would like to thank all of the researchers who submitted their work to this Special Issue. Their contribution is invaluable, and they have equally contributed to make this Special Issue a success. I would also like to express my gratitude to all of the reviewers who helped in the evaluation process of all of the manuscripts, made important suggestions, and contributed to improving the quality of the accepted manuscripts. I would also like to acknowledge the support from the Editorial Office of Electronics who worked extremely hard to maintain the high standard of the journal when the Special Issue was live and supported me during the whole process for a rigorous and timely peer review of the manuscripts.

Conflicts of Interest: The author declares no conflict of interest.

\section{References}

1. Pham, H.H.N.; Hisatake, S.; Minin, O.V.; Nagatsuma, T.; Minin, I.V. Enhancement of spatial resolution of terahertz imaging systems based on terajet generation by dielectric cube. APL Photonics 2017, 2, 056106. [CrossRef]

2. Sun, L.; Zhou, Z.; Zhong, J.; Shi, Z.; Mao, Y.; Li, H.; Cao, J.; Tao, T.H. Implantable, Degradable, Therapeutic Terahertz Metamaterial Devices. Small 2020, 16, 2000294. [CrossRef] [PubMed]

3. O'Hara, J.F.; Withayachumnankul, W.; Al-Naib, I. A review on thin-film sensing with terahertz waves. J. Infrared Millim. Terahertz Waves 2012, 33, 245-291.

4. Pacheco-Peña, V.; Engheta, N.; Kuznetsov, S.; Gentselev, A.; Beruete, M. Experimental Realization of an Epsilon-Near-Zero Graded-Index Metalens at Terahertz Frequencies. Phys. Rev. Appl. 2017, 8, 034036. [CrossRef]

5. Pacheco-Peña, V.; Beruete, M.; Minin, I.V.; Minin, O.V. Terajets produced by dielectric cuboids. Appl. Phys. Lett. 2014, 105, 084102. [CrossRef]

6. Freer, S.; Gorodetsky, A.; Navarro-Cia, M. Beam Profiling of a Commercial Lens-Assisted Terahertz Time Domain Spectrometer. IEEE Trans. Terahertz Sci. Technol. 2021, 11, 90-100. [CrossRef]

7. Karl, N.J.; Mckinney, R.W.; Monnai, Y.; Mendis, R.; Mittleman, D.M. Frequency-division multiplexing in the terahertz range using a leaky-wave antenna. Nat. Photonics 2015, 9, 717-720. [CrossRef]

8. Gutiérrez, J.; Zeljami, K.; Fernández, T.; Pascual, J.P.; Tazón, A. Accurately modeling of zero biased schottky-diodes at millimeterwave frequencies. Electronics 2019, 8, 696. [CrossRef]

9. Pang, S.; Zeng, Y.; Yang, Q.; Deng, B.; Wang, H.; Qin, Y. Improvement in SNR by adaptive range gates for RCS measurements in the THz region. Electronics 2019, 8, 805. [CrossRef]

10. Meng, J.; Zhang, D.; Ji, G.; Yao, C.; Jiang, C.; Liu, S. Design of a $335 \mathrm{GHz}$ frequency multiplier source based on two schemes. Electronics 2019, 8, 948. [CrossRef]

11. Mamrashev, A.; Minakov, F.; Maximov, L.; Nikolaev, N.; Chapovsky, P. Correction of optical delay line errors in terahertz time-domain spectroscopy. Electronics 2019, 8, 1408.

12. Kuznetsov, K.; Klochkov, A.; Leontyev, A.; Klimov, E.; Pushkarev, S.; Galiev, G.; Kitaeva, G. Improved InGaAs and InGaAs/InAlAs Photoconductive Antennas Based on (111)-Oriented Substrates. Electronics 2020, 9, 495. [CrossRef]

13. Feng, J.; Meng, T.; Lu, Y.; Ren, J.; Zhao, G.; Liu, H.; Yang, J.; Huang, R. Nondestructive Testing of Hollowing Deterioration of the Yungang Grottoes Based on THz-TDS. Electronics 2020, 9, 625. [CrossRef]

14. Im, K.-H.; Kim, S.-K.; Jung, J.-A.; Cho, Y.-T.; Woo, Y.-D.; Chiou, C.-P. NDE Terahertz Wave Techniques for Measurement of Defect Detection on Composite Panels of Honeycomb Sandwiches. Electronics 2020, 9, 1360. [CrossRef]

15. Hirakawa, Y.; Yasumoto, Y.; Gondo, T.; Sone, R.; Morichika, T.; Minato, T.; Hojo, M. Application of Terahertz Spectroscopy to Rubber Products: Evaluation of Vulcanization and Silica Macro Dispersion. Electronics 2020, 9, 669.

16. Ji, G.; Zhang, D.; Meng, J.; Liu, S.; Yao, C. Design and Measurement of a 0.67 THz Biased Sub-Harmonic Mixer. Electronics 2020, 9, 161. [CrossRef]

17. Lyu, N.; Zuo, J.; Zhao, Y.; Zhang, C. Terahertz synthetic aperture imaging with a light field imaging system. Electronics 2020, 9, 830. [CrossRef]

18. Zhao, F.; Mao, L.; Guo, W.; Xie, S.; TH Tee, C.A. On-Chip Terahertz Detector Designed with Inset-Feed Rectangular Patch Antenna and Catadioptric Lens. Electronics 2020, 9, 1049. [CrossRef]

19. Xu, L.-L.; Fan, Y.-X.; Liu, H.; Zhang, T.; Tao, Z.-Y. Terahertz Displacement Sensing Based on Interface States of Hetero-Structures. Electronics 2020, 9, 1213. [CrossRef]

20. Nguyen, T.D.; Hong, J.-P. A 350-GHz Coupled Stack Oscillator with -0.8 dBm Output Power in 65-nm Bulk CMOS Process. Electronics 2020, 9, 1214. 